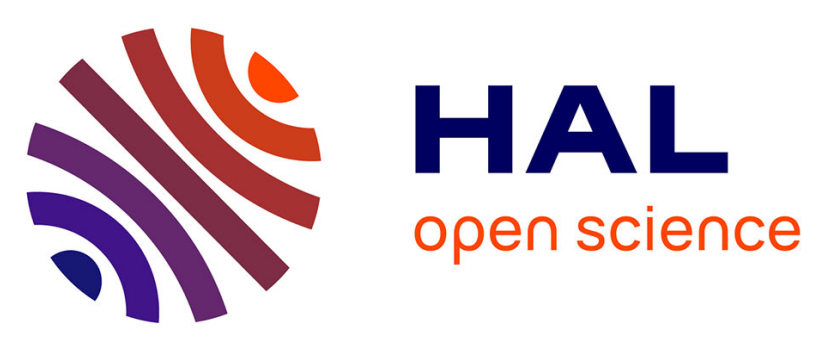

\title{
High-resolution mapping of in-depth soil moisture content through a laboratory experiment coupling a spectroradiometer and two hyperspectral cameras
}

Aurelien Bablet, Françoise Viallefont-Robinet, Stéphane Jacquemoud, Sophie Fabre, Xavier Briottet

\section{To cite this version:}

Aurelien Bablet, Françoise Viallefont-Robinet, Stéphane Jacquemoud, Sophie Fabre, Xavier Briottet. High-resolution mapping of in-depth soil moisture content through a laboratory experiment coupling a spectroradiometer and two hyperspectral cameras. Remote Sensing of Environment, 2019, 236, 111533, p. 1-11. 10.1016/j.rse.2019.111533 . hal-02388844

\section{HAL Id: hal-02388844 https://hal.science/hal-02388844}

Submitted on 2 Dec 2019

HAL is a multi-disciplinary open access archive for the deposit and dissemination of scientific research documents, whether they are published or not. The documents may come from teaching and research institutions in France or abroad, or from public or private research centers.
L'archive ouverte pluridisciplinaire HAL, est destinée au dépôt et à la diffusion de documents scientifiques de niveau recherche, publiés ou non, émanant des établissements d'enseignement et de recherche français ou étrangers, des laboratoires publics ou privés. 
Date: Thursday, November 8, 2019

Title: High-resolution mapping of in-depth soil moisture content through a laboratory experiment coupling a spectroradiometer and two hyperspectral cameras

Authors: A. Bablet ${ }^{\mathrm{a}, \mathrm{b}}$, F. Viallefont-Robinet ${ }^{\mathrm{a},{ }^{*}}$, S. Jacquemoud $^{\mathrm{b}}$, S. Fabre $^{\mathrm{a}}$, X. Briottet $^{\mathrm{a}}$

${ }^{a}$ ONERA/DOTA, Université de Toulouse, 2 avenue Edouard Belin, BP 74025, 31055 Toulouse Cedex 4, France (aurelien.bab@gmail.com, francoise.viallefont@onera.fr, sophie.fabre@onera.fr, xavier.briottet@onera.fr)

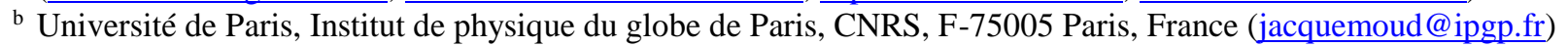

* corresponding author

Keywords: Hyperspectral remote sensing; Soil moisture content; High-resolution water vertical profile; MARMIT model

\section{Highlights:}

- A lab experiment is designed to measure surface and in-depth soil reflectance

- The MARMIT model is used to associate surface moisture content to reflectance

- Vertical maps of soil moisture content are generated on clay loam and sandy soils

- The corresponding profiles are calculated for both soils

- Their evolution over time is analyzed

Journal: Remote Sensing of Environment

\section{Abstract}

A laboratory experiment is set up to study both surface and in-depth soil moisture content (SMC). For that purpose, an aquarium is filled successively with two soils, a clay loam and a sand. Reflectance spectra are acquired in the solar domain (400-2400 nm) on the soil surface using an ASD FieldSpec 3 HR spectroradiometer and in-depth through the aquarium glass wall using two hyperspectral cameras. Successive amounts of water ranging from low to heavy rainfall in a temperate region are uniformly poured into the aquarium. The MARMITforSMC method based on the MARMIT (MultilAyer Radiative Transfer Model for soll reflecTance) model is applied to each reflectance spectrum to determine gravimetric SMC. In particular, vertical profiles of SMC are provided with unprecedented spatial accuracy $(\sim 0.287 \mathrm{~mm})$. The results are compared with volumetric SMC measured by two time-domain reflectometry (TDR) sensors. The in-depth SMC image produced on the sand shows lower values within the first $2 \mathrm{~cm}(5 \%)$ than below (17\%). In contrast, the SMC image produced on the clay loam shows evenly distributed values whatever the position in the aquarium, even $1 \mathrm{~h}$ after moistening. The difference in grain size between the soils explains this result. 


\section{Introduction}

Soil moisture content (SMC) is an important variable of the critical zone (Folke et al., 2004) that plays a key role in weather and climate predictions by controlling exchange and partitioning of water, gas, and energy fluxes between the land surface and the atmosphere (Vereecken et al., 2008; Kornelsen and Coulibaly, 2014). Accurate estimation at various spatial and temporal scales is also important for strategic management of water resources (Vereecken et al., 2016), flood prediction (Ochsner et al., 2013; Schreiner-McGraw et al., 2016), drought monitoring (Bolten et al., 2010) and yield forecasting (de Wit and van Diepen, 2007) in agriculture. However, SMC greatly varies in time and space due to inherent variations in soil hydraulic properties (Montzka et al., 2011), precipitation rates (Koster et al., 2004; Rosenbaum et al., 2012), topography (Joshi and Mohanty, 2010; Jana and Mohanty, 2012; Schröter et al., 2015), and vegetation characteristics (Famiglietti et al., 1998; Gaur and Mohanty, 2013). Depending on the wavelength range, remote sensing is likely to provide information about surface or in-depth water content. Indeed, in the solar domain, sunlight only penetrates through the first micrometers or millimeters of the soil (e.g., Perkins, 1963; Woolley and Stoller, 1978; Tester and Morris, 1987; Liang et al., 1997; Ciani et al., 2005), thus the information collected is surface SMC. According to the frequency, microwaves go deeper into the ground, thus the information collected is volume SMC. In situ measurements generally also correspond to volume SMC. Both surface and volume SMC are valuable information, according to the application, but the remote sensing community has seldom jointly studied them because the two wavelengths domains are separated in terms of signal processing. Sadeghi et al. (2017) pioneered the measurement of high-resolution soil water content profiles over seven soils covering a wide range of textures. They set up a laboratory experiment involving a broadband camera operating in the shortwave infrared (900-1700 nm) and a novel TDR array. They applied a relationship derived from the Kubelka-Munk theory to study water flux profiles with an unprecedented accuracy. 
This article presents a laboratory experiment imagined nearly at the same period to assess both

surface SMC and in depth SMC profiles thanks to a spectrometer, two hyperspectral cameras, and a radiative transfer model called MARMIT (Bablet et al., 2018). We poured controlled amounts of water on two different soils and measured the evolution of the SMC profiles with high spatial resolution. Section 2 presents the laboratory experiment and the calibration of the radiometric data. In Section 3 , the spectral reflectance of the soils measured on the surface is compared to the one imaged on the side of the aquarium; we also quantify the evolution of the SMC in time thanks to the MARMITforSMC method. The results are discussed in Section 4.

\section{Material, measurements and processing}

\subsection{Experimental set-up}

As a first trial, two different soils, a clay loam and a sand, have been selected for this experiment. Their main characteristics are summarized in Table 1. Although the fraction passing a $2 \mathrm{~mm}$ sieve was collected for each soil, the sand was mostly composed of large white grains of homogeneous size while the clay loam consisted of smaller brown grains of heterogeneous sizes. Both soils were successively poured into an aquarium (dimensions: $27.5 \mathrm{~cm}$ long $\times 13 \mathrm{~cm}$ wide $\times 20 \mathrm{~cm}$ high) with glass walls 1.5 $\mathrm{cm}$ thick in their center, the corners being slightly thicker than the faces. The aquarium was put on a linear motion platform.

Table 1. Some characteristics of the soil samples.

\begin{tabular}{cccccc}
\hline Soil sample & \multicolumn{3}{c}{ Texture } & Composition & Bulk density \\
\cline { 2 - 4 } & Clay & Silt & Sand & & \\
\hline Clay loam & $35.8 \%$ & $40.3 \%$ & $23.9 \%$ & & \\
Sand & $0 \%$ & $0 \%$ & $100 \%$ & $\mathrm{SiO}_{2}(98.5 \%)$ & $1.5 \mathrm{~g} \mathrm{~cm}^{-3}$ \\
\hline
\end{tabular}

The spectral radiance was measured from above (surface measurement) and from one side of the aquarium (in-depth measurement). An ASD FieldSpec $3 \mathrm{HR}$ spectroradiometer equipped with a $5^{\circ}$ aperture lens was used for the nadir acquisitions. The detector being located at a distance of $37 \mathrm{~cm}$ from the soil, the footprint is a disk of about $3.2 \mathrm{~cm}$ in diameter. Two halogen lamps positioned on each side 
of the spectroradiometer lit the soil from above with an incidence angle of $10^{\circ}$. A third halogen lamp lit the side of the aquarium. Two hyperspectral cameras fixedly positioned in front of the aquarium were used for the lateral acquisitions. They measure the radiance of a vertical pixel line in the visible-near infrared (HySpex VNIR-1600) and in the shortwave infrared (HySpex SWIR-320m-e). The pixel size of the VNIR camera is $0.06 \mathrm{~mm} \times 0.12 \mathrm{~mm}$ while that of the SWIR camera is $0.287 \mathrm{~mm} \times 0.287 \mathrm{~mm}$. The two cameras imaged the scene line-by-line while the aquarium passed in front of them, like a pushbroom scanner. The images consist of 720 vertical lines in the VNIR and 360 vertical lines in the SWIR. Their co-registration was helped by small pieces of duct tape on the outer glass wall of the aquarium. A common area $10.2 \mathrm{~cm}$ long and $9.1 \mathrm{~cm}$ wide was finally delimited to study the water profiles. The experimental setup is illustrated in Fig. 1 and a summary of the main characteristics of the optical sensors is provided in Table 2.

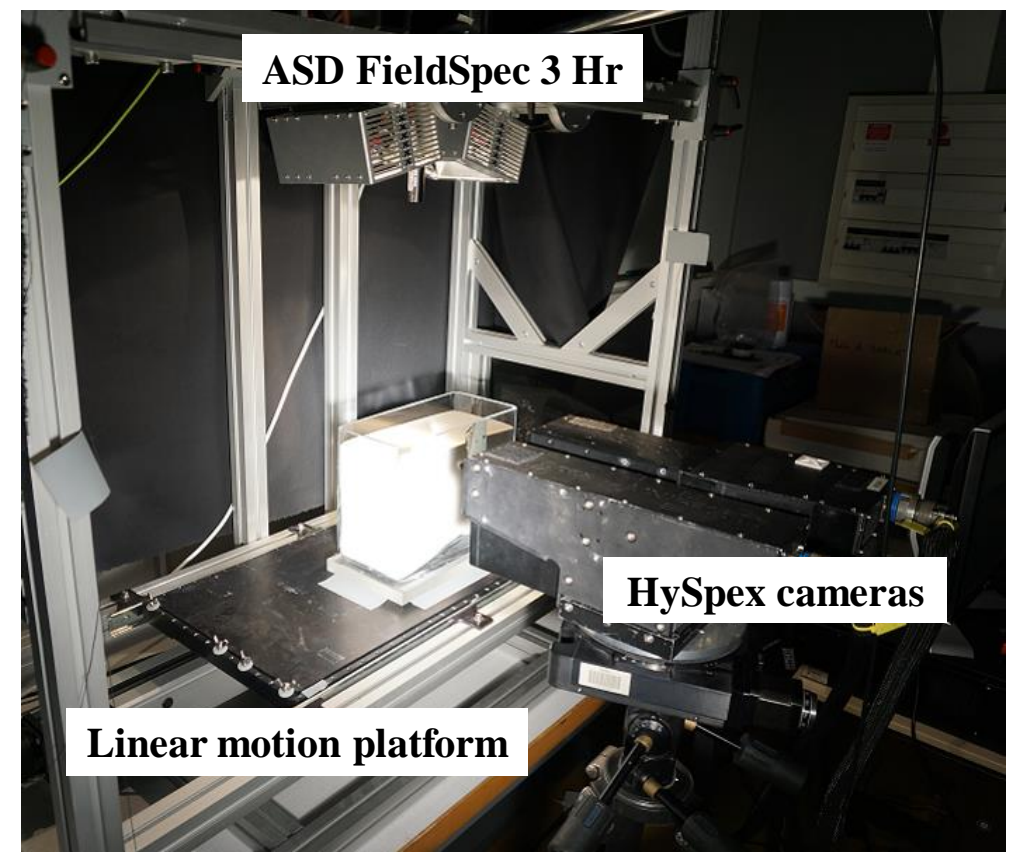

Fig. 1. Experimental set-up showing the two hyperspectral cameras, the spectroradiometer, the two lamps illuminating the soil from above, and the aquarium on the linear motion platform.

Table 2. Main characteristics of the optical sensors.

\begin{tabular}{lcccc}
\hline Sensor & $\begin{array}{c}\text { Spectral range } \\
(\mathrm{nm})\end{array}$ & $\begin{array}{c}\text { Spectral sampling } \\
\text { interval }(\mathrm{nm})\end{array}$ & $\begin{array}{c}\text { Number of spectral } \\
\text { bands }\end{array}$ & $\begin{array}{c}\text { Aperture angle }\left(^{\circ}\right) \text { or field } \\
\text { of view }(\mathrm{mrad})\end{array}$ \\
\hline ASD & $350-2500$ & $1.4-2$ & 1512 & $5^{\circ}$ \\
VNIR camera & $414-992$ & 3.7 & 160 & $0.18 \mathrm{mrad}$ \\
SWIR camera & $966-2500$ & 6 & 256 & $0.75 \mathrm{mrad}$ \\
\hline
\end{tabular}


Finally, after each scan, two TDR (Time Domain Reflectometry) probes were inserted in the soil from

103 above to measure volume moisture content at two different depths: the Trime-Pico 64/32 probe $(5 \mathrm{~cm}$ 104 long pins) and the FieldScout TDR 100 probe (3.7 cm long pins). According to the user manuals, soil 105 moisture is detected up to a distance of $3 \mathrm{~cm}$ around the pins, which corresponds to a surveyed cylinder 106 shape volume of $141 \mathrm{~cm}^{3}$ for the Trime-Pico probe and $104.6 \mathrm{~cm}^{3}$ for the FieldScout TDR. These values 107 are to compare to the volume of the aquarium that is $7150 \mathrm{~cm}^{3}$. The probe accuracy provided by the 108 manufacturers is $\pm 3 \%$ moisture by volume.

\subsection{Measurement protocol}

The measurements are carried out in four stages:

1) A known amount of water is uniformly and softly poured onto the soil using a plastic box drilled with $2 \mathrm{~mm}$ diameter holes. It limits the change in appearance of the soil surface, and it prevents water from flowing along the walls of the aquarium. After moistening, the aquarium is put back on the linear motion platform in exactly the same position.

2) The radiance spectrum of the soil surface is measured with the ASD spectroradiometer. Each spectrum is actually an average of 50 spectra. During acquisition, the lamp illuminating the aquarium from the side and used for the HySpex measurements is obscured by an opaque shield. 3) Hyperspectral images of the soil are acquired with the line-scan HySpex cameras by translating the aquarium laterally.

4) The two TDR probes are then inserted into the soil at one side of the aquarium to measure volumetric soil moisture content.

Once the cycle is over, a given amount of water $(\sim 100 \mathrm{~g})$ is added and new measurements are performed (steps 1 to 4 ) after the water front stabilizes. A total of nine cycles of measurements were made corresponding to the dry soil plus eight moisture levels (Table 3). The waiting time between two cycles was much longer for the clay loam soil (up to 50 minutes) than for the sandy soil (up to 15 minutes) so the duration of one cycle varies according to soil type and moistening level. The water mass (g) was translated into rainfall values $(\mathrm{mm})$ for comparison with natural precipitations. For instance, 
Météo-France, the French national meteorological service, indicates a monthly cumulative rainfall of

$13055 \mathrm{~mm}$ in Paris: a light rain corresponds to a rainfall of 1 to $3 \mathrm{~mm} \mathrm{~h}^{-1}$, an average rain to a rainfall of 4-

$1317 \mathrm{~mm} \mathrm{~h}^{-1}$, and a heavy rain to a rainfall of $8 \mathrm{~mm} \mathrm{~h}^{-1}$ or more. During extreme events, these values may

132 exceed $100 \mathrm{~mm} \mathrm{~h}^{-1}$. The quantities of water poured into the aquarium during our experience

133 consequently ranged from light to heavy rainfalls in a temperate region.

134

135

136

137

Table 3. Quantity of water poured over the two soils at each moistening stage. $\Delta t$ is the elapsed time between the addition of water and the measurement with the cameras.

\begin{tabular}{|c|c|c|c|c|c|c|c|c|}
\hline \multirow{2}{*}{$\begin{array}{c}\text { Moisture } \\
\text { level }\end{array}$} & \multicolumn{4}{|c|}{ Clay loam } & \multicolumn{4}{|c|}{ Sand } \\
\hline & $\begin{array}{c}\Delta \mathrm{t} \\
(\mathrm{min})\end{array}$ & $\begin{array}{l}\text { Added water } \\
\text { mass }(\mathrm{g})\end{array}$ & $\begin{array}{l}\text { Cumulative } \\
\text { water (g) }\end{array}$ & $\begin{array}{l}\text { Cumulative } \\
\text { water }(\mathrm{mm})\end{array}$ & $\begin{array}{c}\Delta \mathrm{t} \\
(\mathrm{min})\end{array}$ & $\begin{array}{c}\text { Added water } \\
\text { mass (g) }\end{array}$ & $\begin{array}{l}\text { Cumulative } \\
\text { water (g) }\end{array}$ & $\begin{array}{l}\text { Cumulative } \\
\text { water (mm) }\end{array}$ \\
\hline$\# 1$ & 18 & 96.5 & 96.5 & 2.7 & 9 & 100.3 & 100.3 & 2.8 \\
\hline \#2 & 8 & 98.2 & 194.7 & 5.5 & 8 & 105.9 & 206.2 & 5.8 \\
\hline \#3 & 9 & 108.2 & 302.9 & 8.5 & 7 & 99.1 & 305.3 & 8.5 \\
\hline \#4 & 16 & 99.6 & 402.5 & 11.3 & 6 & 107.0 & 412.3 & 11.5 \\
\hline \#5 & 17 & 115.3 & 517.8 & 14.5 & 10 & 112.5 & 524.8 & 14.7 \\
\hline \#6 & 14 & 127.2 & 645.0 & 18.1 & 10 & 101.1 & 625.9 & 17.5 \\
\hline \#7 & 48 & 180.1 & 825.1 & 23.1 & 12 & 109.6 & 735.5 & 20.6 \\
\hline$\# 8$ & 50 & 208.1 & 1033.2 & 28.9 & 15 & 209.7 & 945.2 & 26.5 \\
\hline
\end{tabular}

\subsection{Data pre-processing chain}

Data production requires a series of pre-processing operations. The first step is the coregistration of the VNIR and SWIR images acquired by the two cameras in order to cover the entire reflective domain. Their instantaneous fields of view are different, so are the spatial resolutions of the images. Thus, preprocessing begins with the degradation of the spatial resolution of the VNIR image in order to match that of the SWIR image. This resampling is achieved by using the nearest neighbor filter that preserves the spectral information. The two images are then co-registered using GeFolki, a multi-scale registration software developed by ONERA that exploits the few overlapping spectral bands between the two images (Brigot et al., 2016). It results in a hyperspectral data cube containing $320 \times 300$ pixels with a side length of $0.287 \mathrm{~mm}(9.1 \mathrm{~cm} \times 8.5 \mathrm{~cm}$ image $)$ in the reflective domain. Each pixel contains a continuous radiance spectrum made of 408 narrow bands between $414 \mathrm{~nm}$ and $2400 \mathrm{~nm}$ (Fig. 2). The spectral sampling is $3.26 \mathrm{~nm}$ for the VNIR camera and $5.45 \mathrm{~nm}$ for the SWIR camera. The last eight spectral bands of the VNIR camera, also measured by the SWIR camera, are removed in order to avoid spectral domain overlap. Fig. 2 displays the radiance of a pixel extracted from the dry sand image. 


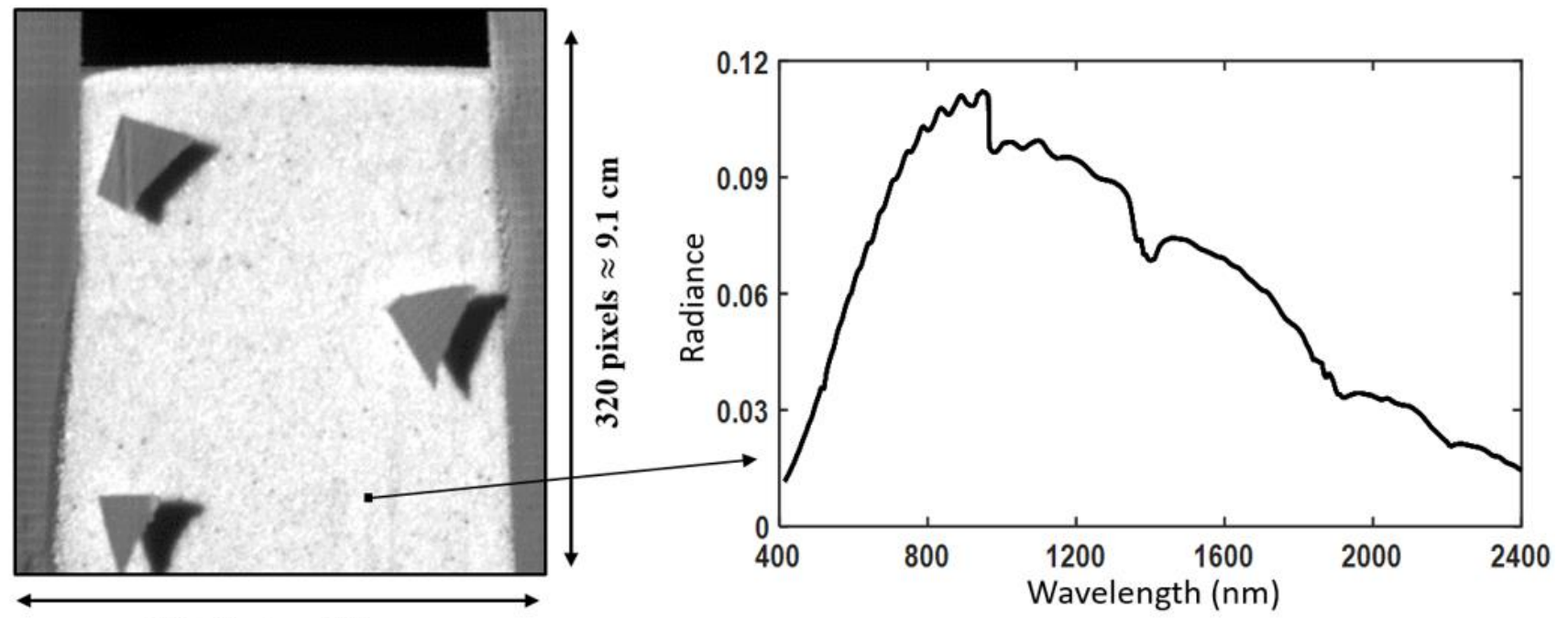

300 pixels $\approx 8.5 \mathrm{~cm}$

Fig. 2. (Left) image of the dry sand in the aquarium obtained with the HySpex cameras at $966 \mathrm{~nm}$ with the pieces of duct tape in grey and (right) radiance spectrum of a pixel of the image expressed in $\mathrm{W} \mathrm{m}^{-2} \mathrm{sr}^{-1} \mu \mathrm{m}^{-1}$.

A jump in the radiance spectrum is clearly visible at the wavelength of $966 \mathrm{~nm}$ corresponding to the boundary between the VNIR and SWIR images (Fig. 2). That problem, common in radiometry, is expected to disappear when calculating the reflectance factor of the soil-aquarium system:

$$
R_{s-a}=\frac{L_{s-a}}{L_{r p}} \times R_{r p}
$$

with $R_{s-a}$ and $L_{s-a}$ the reflectance and the radiance of the soil-aquarium system, $R_{r p}$ and $L_{r p}$ the reflectance and the radiance of the reference panel (Spectralon $\left.{ }^{\circledR}\right)$. The relevant quantity is nevertheless the soil reflectance. To remove the contribution of the aquarium glass wall, we placed a sheet of white paper, the optical properties of which are known, successively inside and outside the aquarium. To first order, the transmittance of the aquarium glass wall equals:

$$
\tau(\lambda)=\frac{R_{\text {paper }+ \text { glass }}}{R_{\text {paper }}}
$$

166 with $R_{\text {paper+glass }}$ and $R_{\text {paper }}$ respectively the reflectance of the paper behind and in front of the glass 


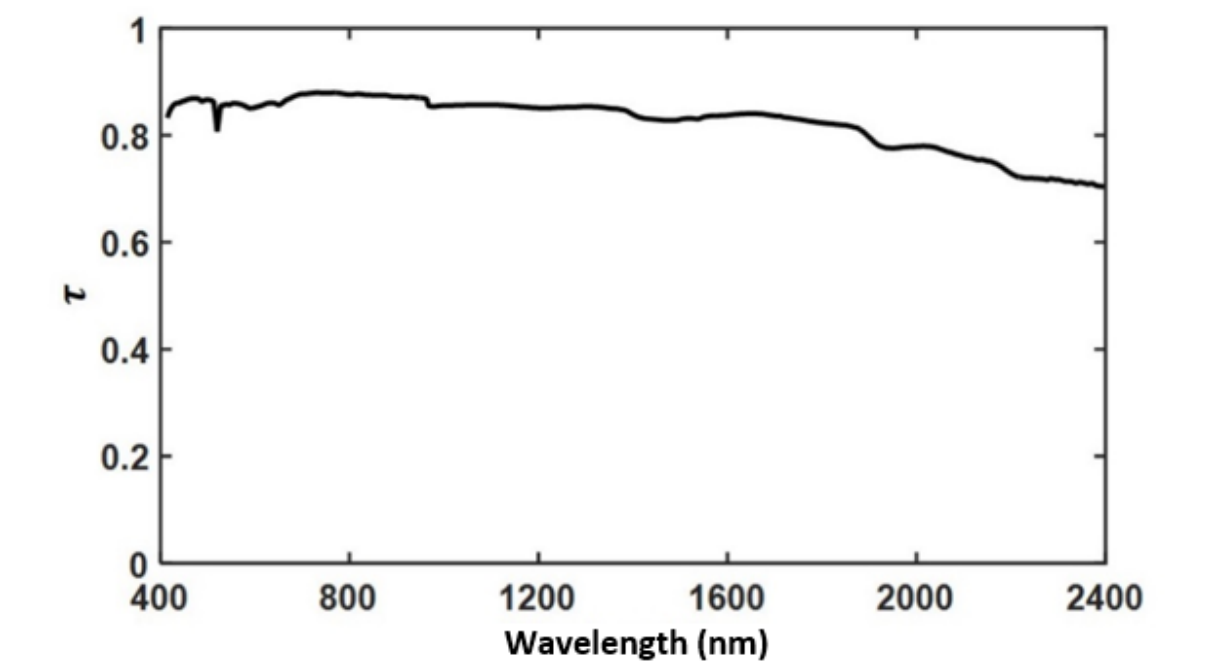

Fig. 3. Spectral transmittance $\tau$ of the aquarium wall.

170 Then each reflectance spectrum of the soil-aquarium system is divided by $\tau(\lambda)$ to calculate the soil 171 reflectance only. However, although reduced after conversion to reflectance and correction of the 172 aquarium transmittance, the jump at $966 \mathrm{~nm}$ was still noticeable (Fig. 4). This artifact may have several 173 causes including camera instability or non-nominal shutter operation of one of the two cameras. To 174 remove it, we compared the reflectance of the dry sand acquired vertically with the ASD with that 175 acquired laterally with the cameras. The sand was used rather than the clay loam because the grain size, 176 which is known to control soil reflectance (e.g., Okin \& Painter, 2004; Sadeghi et al., 2018), is more 177 homogeneous. Fig. 4 shows a good agreement in the SWIR but an overestimation of the reflectance 178 spectrum by the HySpex VNIR camera. According to the pixel, this overestimation varies between $0 \%$ and 5\%. Therefore, the reflectance ratio $C$ defined as

$$
C=\frac{R(\lambda=963.3 \mathrm{~nm})}{R(\lambda=966.7 \mathrm{~nm})}
$$

182 is calculated for each pixel of the image at the junction between the two cameras and the VNIR spectrum

183 is divided by $C$ to obtain a continuous spectrum (Fig. 4). This pre-processing is a prerequisite for 184 analyzing the spectra acquired by the HySpex cameras. 


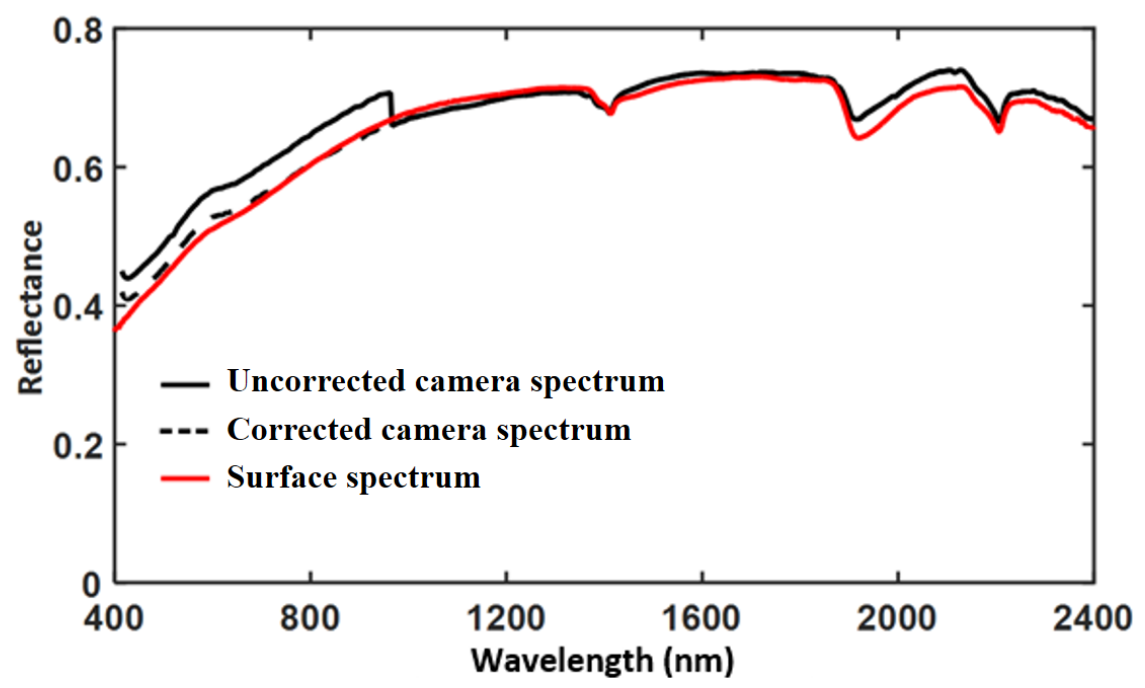

Fig. 4. Uncorrected reflectance spectrum of the sand acquired by the cameras compared to the reflectance spectrum acquired on the surface by the ASD and to the corrected spectrum of the same soil in the aquarium.

\section{Results}

\subsection{Reflectance analysis}

\subsubsection{Stability}

The impact on the reflectance of a variation in illumination during the experiment was first assessed.

191 Two phenomena are likely to occur: 1) a drift of the luminous intensity of the lamps, and 2) a variation

192 of the ambient light of the laboratory that was in the half-light. These effects can be theoretically

193 corrected by regular measurements of the radiance of the Spectralon ${ }^{\circledR}$ panel but, due to experimental

194 constraints, only one spectrum was acquired at the beginning of the experiment. In order to appraise

195 this impact, we considered a deep zone in the sand that remains dry from measurements \#1 to \#5 (Fig.

196 5a), as well as one of the three pieces of duct tape (Fig. 5b). In both cases, the change in reflectance was

197 less than $4 \%$.

198 
(a)

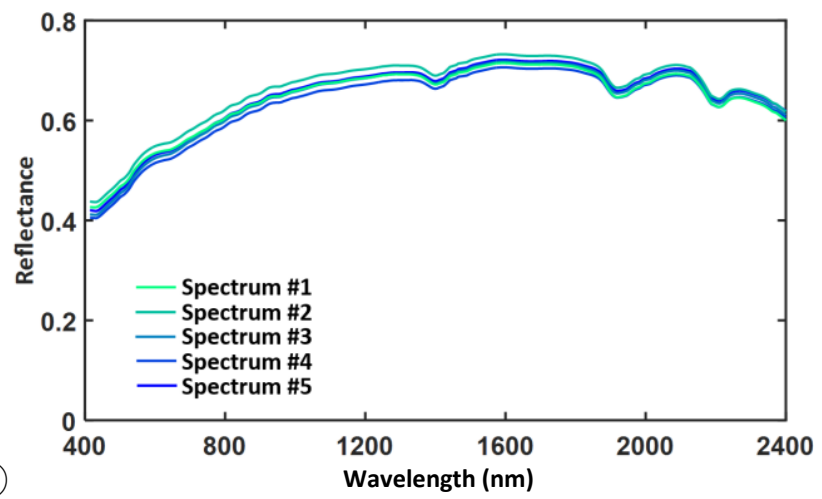

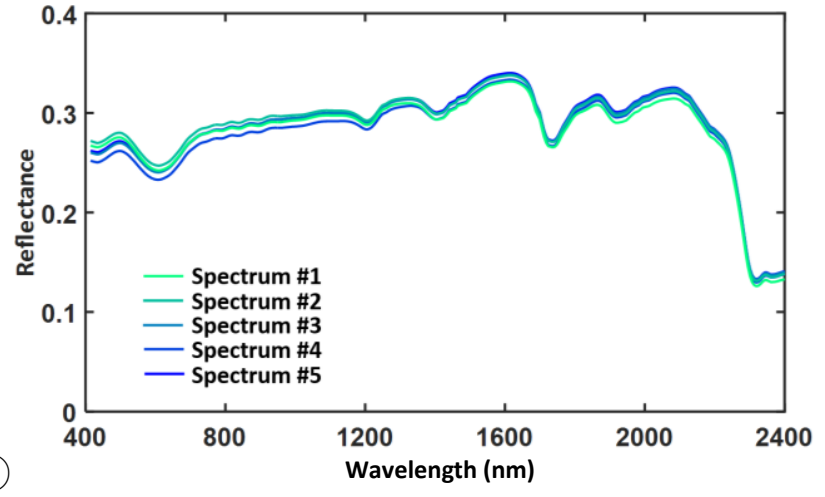

199

Fig. 5. Reflectance variations of (a) dry sand and (b) duct tape at moisture levels \#1 to \#5.

\subsubsection{Vertical variation}

The change in soil reflectance as a function of depth provides us with information on its variation in relation to surface reflectance. To study that relationship, we divided the images into twenty contiguous rectangles (78 pixels $\times 15$ pixels) having the same surface area $(2.24 \mathrm{~cm} \times 0.43 \mathrm{~cm})$ as illustrated by Fig. 6.

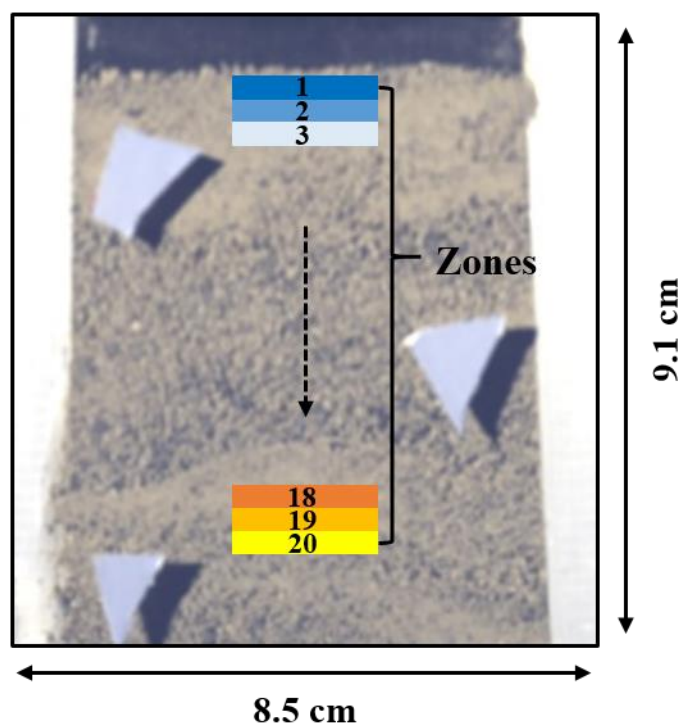

Fig. 6. Representation of the twenty rectangles on the RGB image of the dry clay loam. The dark blue rectangle, referred as Zone 1, is the closest to the surface while the yellow rectangle, referred as Zone 20, is the farthest. In light grey, the three pieces of duct tape.

Prior to comparing the reflectance of wet and dry areas, one can analyze the reflectance of the dry soils. Fig. 7 superimposes the reflectance spectrum of the surface on the average reflectance spectrum measured in each layer. The variability of dry soil reflectance is higher for the clay loam than for the 
210 sand, probably due to a larger range of grain size. For the various moisture levels, the differences in 211 reflectance levels can be only attributed to soil water content since the other soil properties influencing 212 reflectance (mineralogical composition, organic matter, texture, homogeneity ...) are invariant during 213 the experiment. For the clay loam, the lowest reflectance spectrum that corresponds to the wettest soil 214 layer remains close to the surface and it matches closely the ASD reflectance spectrum. For the sand, it 215 is found deeper in the aquarium as water is poured in. 

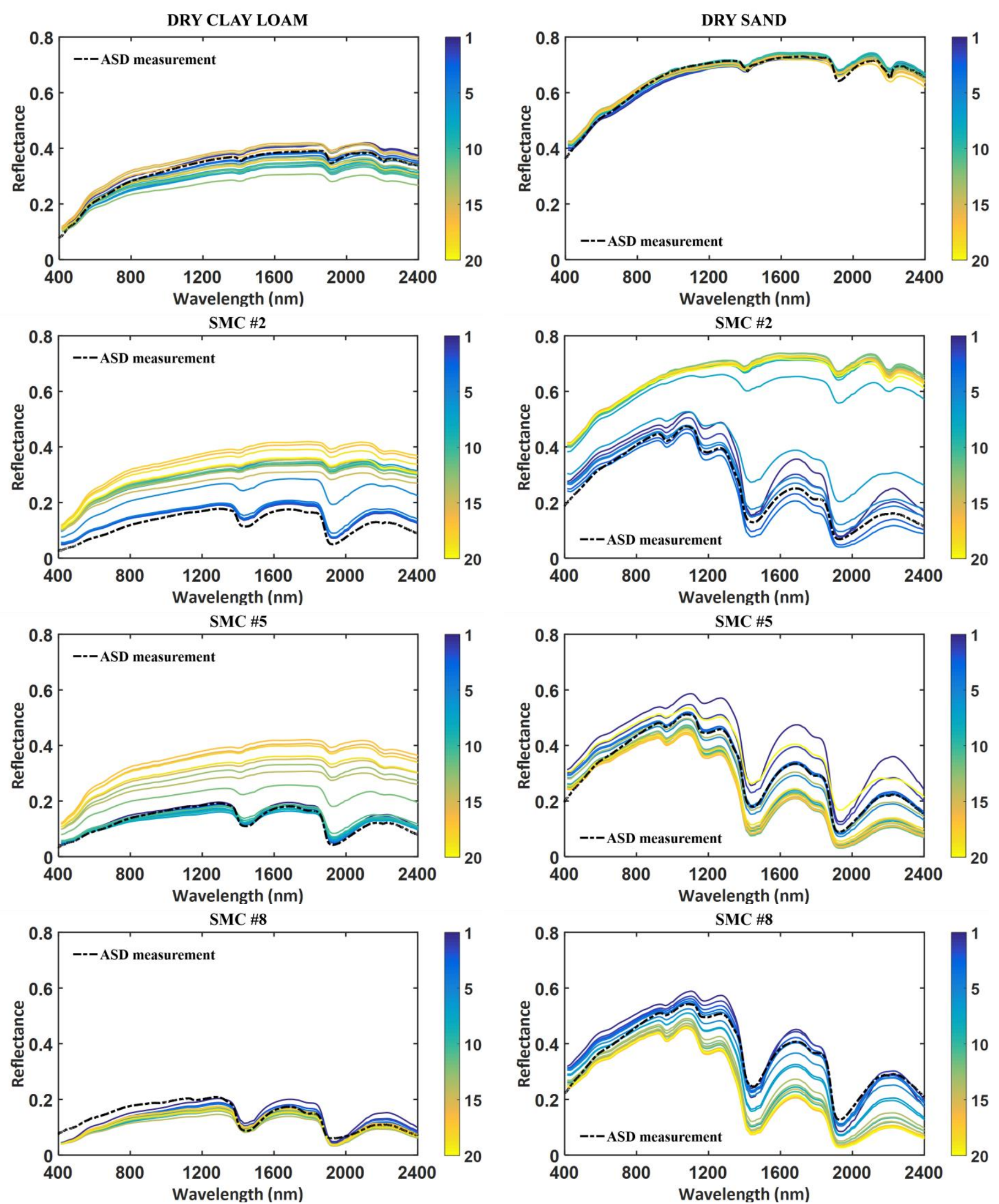

Fig. 7. Average reflectance spectra of the twenty rectangular zones for the dry and wet soils at moisture levels \#2, \#5, and \#8. In dark blue, the closest to the surface (Zone 1) and in yellow, the farthest (Zone 20). On the left, the clay loam and on the right, the sand.

218 We also plotted the standard deviation of the reflectance of all pixels in a zone (Fig. 8). It is higher 219 for the dry clay loam (8\% maximum for Zone 12) than for the dry sand (3\% maximum for Zone 3). One 
220 can also note that it is lowest at high moisture levels (saturated soil). In the transition zones where the

221 soil is partially wet, it is higher for the sand than for the clay loam, suggesting that the distribution of 222 water in the sand is highly variable within the same zone. The changes in reflectance due to the 223 penetration of water into both soils are analyzed qualitatively. To go further, the next section will focus 224 on soil moisture variation during infiltration. 

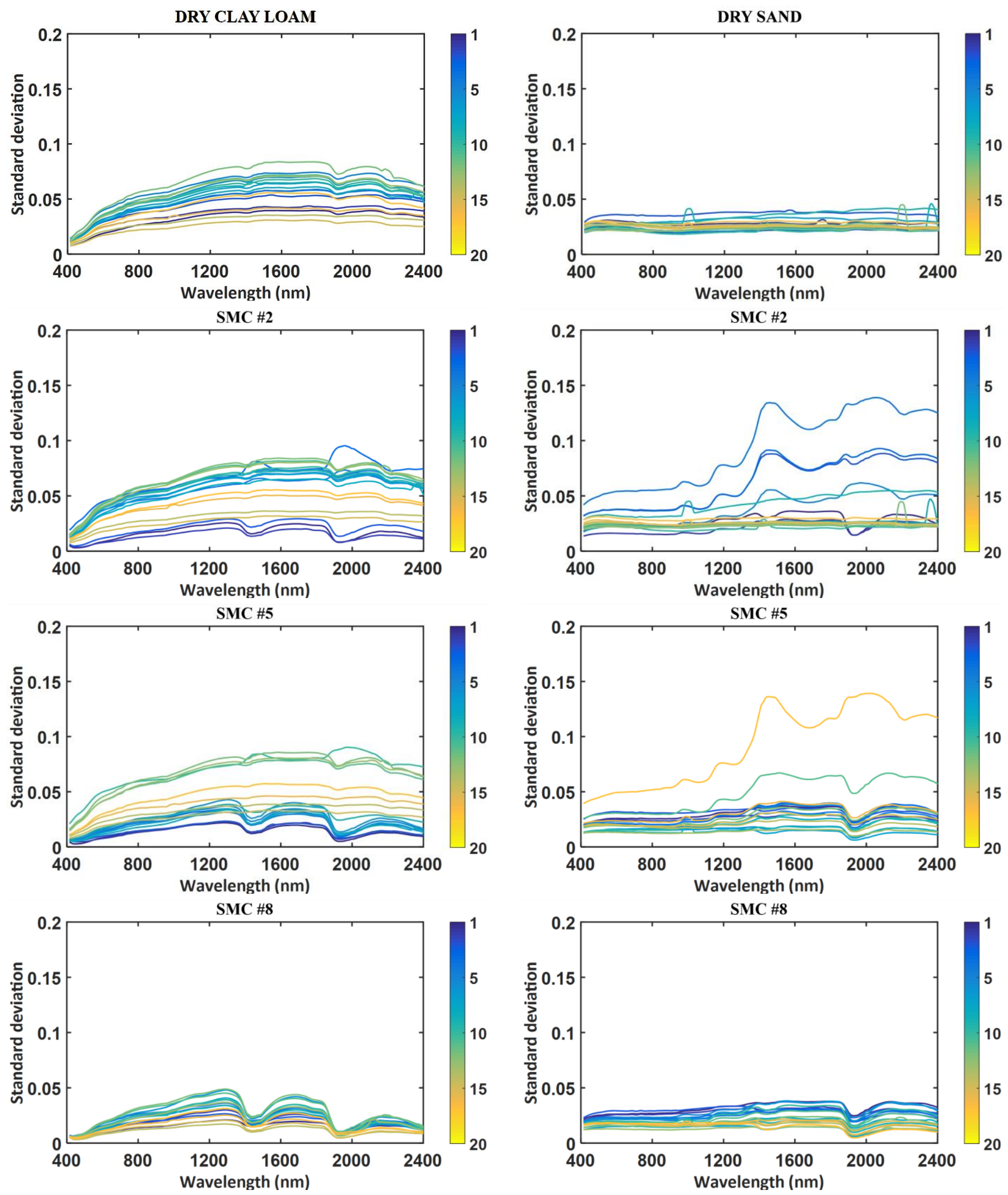

Fig. 8. Standard deviation of the reflectance spectra in the twenty rectangular zones for the dry and wet soils at moisture levels \#2, \#5, and \#8. In dark blue, the closest to the surface (Zone 1) and in yellow, the farthest (Zone 20). On the left, the clay loam and on the right, the sand. 
MARMIT is a radiative transfer model that simulates the reflectance spectrum of a wet soil in the 231 solar domain assuming that the reflectance spectrum of the dry soil is known (Bablet et al., 2018). It considers a wet soil as a dry soil covered with a thin film of water characterized by two parameters: the thickness of the film $L$ and the efficiency $\varepsilon$ defined as the proportion of the ground covered by water. 234 These two parameters are retrieved by fitting MARMIT to the measured reflectance spectrum. A 235 calibration of the model is required for each soil: it consists in measuring reflectance spectra at various 236 SMC and in linking SMC and the mean water thickness $\varphi=L \times \varepsilon$ by a sigmoid function (Fig. 9):

$$
S M C_{\text {clay loam }}=\frac{45.3}{1+9.4 \times e^{-403 \times \varphi}}
$$

$$
S M C_{\text {sand }}=\frac{23.6}{1+9.0 \times e^{-39.4 \times \varphi}}
$$

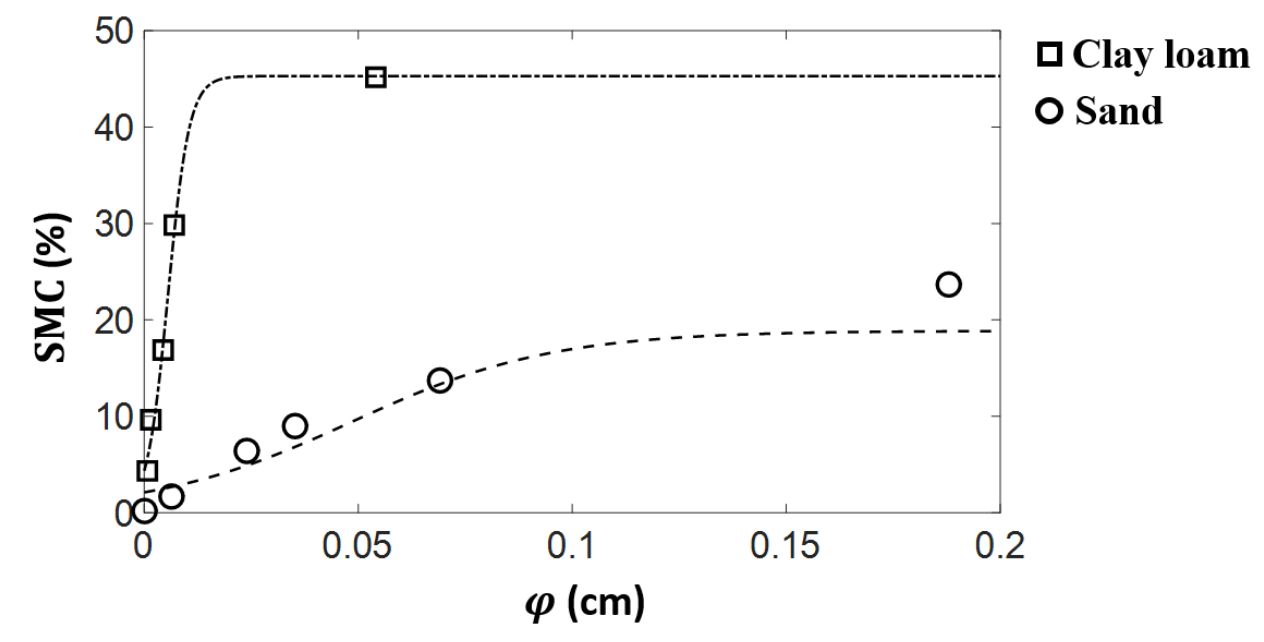

Fig. 9. Variation of SMC as a function of the mean water thickness for the clay loam and the sand. The lines correspond to Eqs. (4) and (5) respectively.

Note that the soil samples used in this calibration phase were placed in Petri dishes $1 \mathrm{~cm}$ deep, 242 therefore, the estimated SMC is strictly speaking not a surface attribute but actually a volume attribute. 243 Thanks to Eqs. (4) and (5), one can map SMC in the aquarium using the hyperspectral cameras, and at 244 the same time, assess SMC on the soil surface using the ASD spectroradiometer. These two quantities 245 have never been measured simultaneously before. 


\subsubsection{Check for consistency}

Applying Eqs. (4) and (5) for the aquarium experiment implies that the water distribution is the same

as in the Petri dishes. Moreover, since the measurement protocols differ in the two experiments

(illumination angle and distance of the sensors from the soil sample), it is imperative to verify that the

reflectance spectra of the dry soils are similar both for the calibration and experiment samples. A

(Fig. 10b). The discrepancy is more important in the near-infrared and in the short-wave infrared than

in the visible region of the electromagnetic spectrum. It has been shown that the influence of the grain

size on reflectance is minimum in the visible and maximum in the infrared (e.g., Okin and Painter, 2004;

Sadeghi et al., 2018). We conclude from this that the differences in reflectance for the clay loam are measured reflectance.
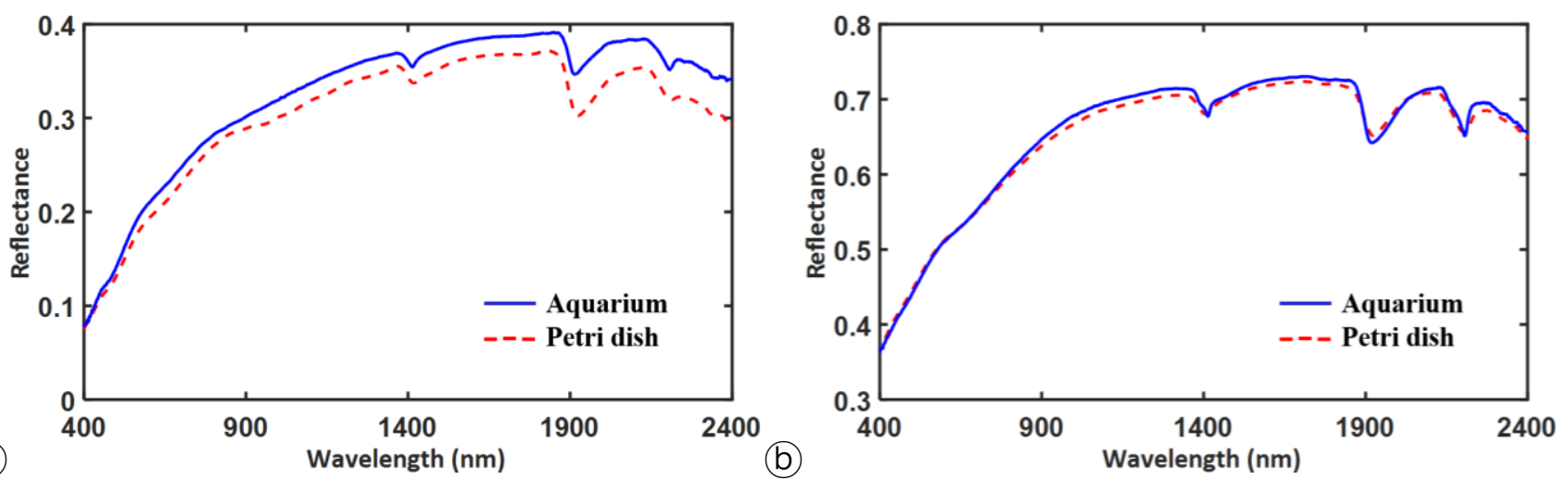

Fig. 10. Differences between the spectral reflectances acquired with the ASD for soil in the Petri dish and in the aquarium (dash-dot line in Fig. 7) for (a) the dry clay loam and (b) the dry sand.

\subsubsection{SMC maps and profiles versus TDR measurements}

The input parameters $L$ and $\varepsilon$ of MARMIT are first estimated by inversion of the model on the soil

reflectance spectra acquired both on the surface and the side of the aquarium. Then, the values of $\varphi=$

$L \times \varepsilon$ are injected into Eqs (4) and (5) to calculate SMC (Figs 11 and 12). The estimation error is about 
through the origin (Fig. 9), which may lead to uncertainties for low water content (SMC $<5 \%$ for the

clay loam and SMC $<3 \%$ for the sand). Water content profiles are then easily obtained by averaging the SMC values on each horizontal pixel line of the hyperspectral images. The integrated values of soil moisture content $\left(\mathrm{SMC}_{\mathrm{i}}\right)$ determined using the water content maps can be compared with the values measured by the FieldScout TDR $100\left(\mathrm{SMC}_{\mathrm{fs}}\right)$ and the Trime-Pico 64/32 ( $\left.\mathrm{SMC}_{\mathrm{tp}}\right)$ probes just after the radiometric measurements. These measurements enable us to assess integrated SMC between 0 and 3.7 $\mathrm{cm}$ and between 0 and $5 \mathrm{~cm}$, respectively (Table 4). The values of the two probes agree for the clay loam but are somewhat different for the sand. Such a difference was expected but the evolution of the 274 measurements with the successive "rain falls" doesn't follow the increase and decrease suggested by 275 the profiles, with a decrease occurring earlier for the FieldScout. Moreover, there is no apparent 276 relationship between $\mathrm{SMC}_{\mathrm{i}}$ and the probe measurements. Their representativeness may be poor in such 277 a context due to the successive driving and digging up of the probes, which disturb the soil layers. These 278 effects may vary from one soil to another.

279 The profiles extracted from the images agree with the literature: after moistening, water is evenly 280 distributed in the clay loam when the sand displays a wide disparity, as noticed by Edwards et al. (2013). 281 At the highest moisture level (\#8), SMC is less than $5 \%$ in the first $2 \mathrm{~cm}$ of the sand whereas it equals $28217 \%$ on average below. For the clay loam, the water content equals $45 \%$ at surface and at depth when 283 the soil is saturated with water.

Table 4. Volume soil moisture content $\left(\mathrm{cm} \mathrm{cm}^{-3} \times 100\right)$ measured by the two TDR probes: $\mathrm{SMC}_{\mathrm{fs}}$ for the FieldScout TDR 100 (3.7 cm pins) and $\mathrm{SMC}_{\mathrm{tp}}$ for the Trime-Pico 64/32 (5 cm pins).

\begin{tabular}{ccccc}
\hline Moisture level & \multicolumn{2}{c}{ Clay loam } & \multicolumn{2}{c}{ Sand } \\
\cline { 2 - 5 } & $\mathrm{SMC}_{\mathrm{fs}}$ & $\mathrm{SMC}_{\mathrm{tp}}$ & $\mathrm{SMC}_{\mathrm{fs}}$ & $\mathrm{SMC}_{\mathrm{tp}}$ \\
\hline Dry soil & 0.0 & 0.3 & 0.0 & 0.3 \\
$\# 1$ & 8.4 & 4.3 & 1.9 & 1.3 \\
$\# 2$ & 13.8 & 12.2 & 2.2 & 5.1 \\
$\# 3$ & 28.0 & 29.9 & 3.1 & 6.5 \\
$\# 4$ & 34.3 & 32.5 & 5.4 & 17.0 \\
$\# 5$ & 35.7 & 37.2 & 5.1 & 21.5 \\
$\# 6$ & 36.5 & 38.9 & 4.8 & 18.7 \\
$\# 7$ & 37.0 & 39.0 & 4.5 & 19.1 \\
$\# 8$ & 40.0 & 44.5 & 4.6 & 20.7 \\
\hline
\end{tabular}



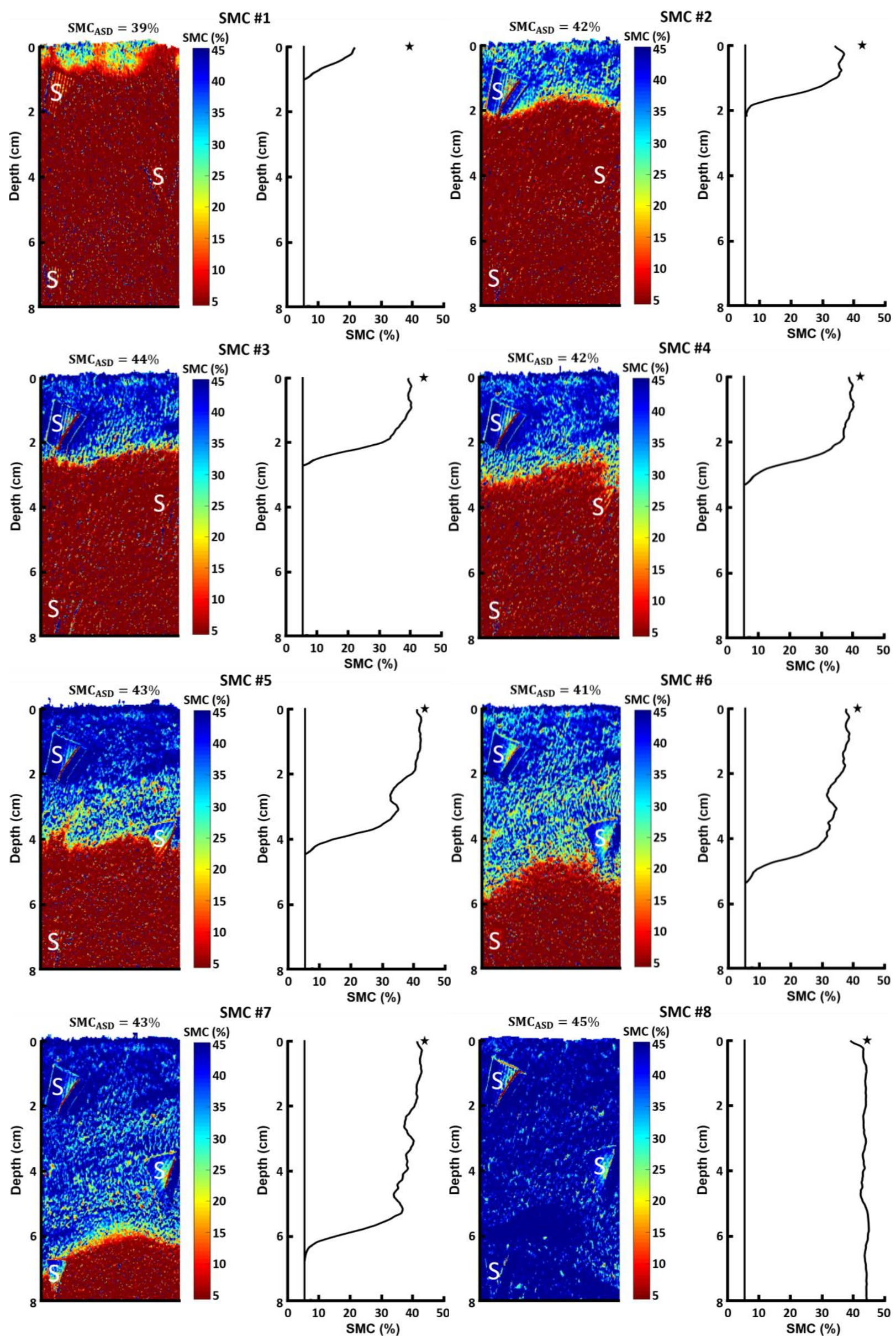

Fig. 11. SMC maps of the clay loam as a function of the amount of water poured and associated water content profiles. From top left to bottom right: moisture levels \#1 to \#8 (Table 2). $\mathrm{S}=$ piece of duct tape. The star points the SMC value measured at the top of the soil. 

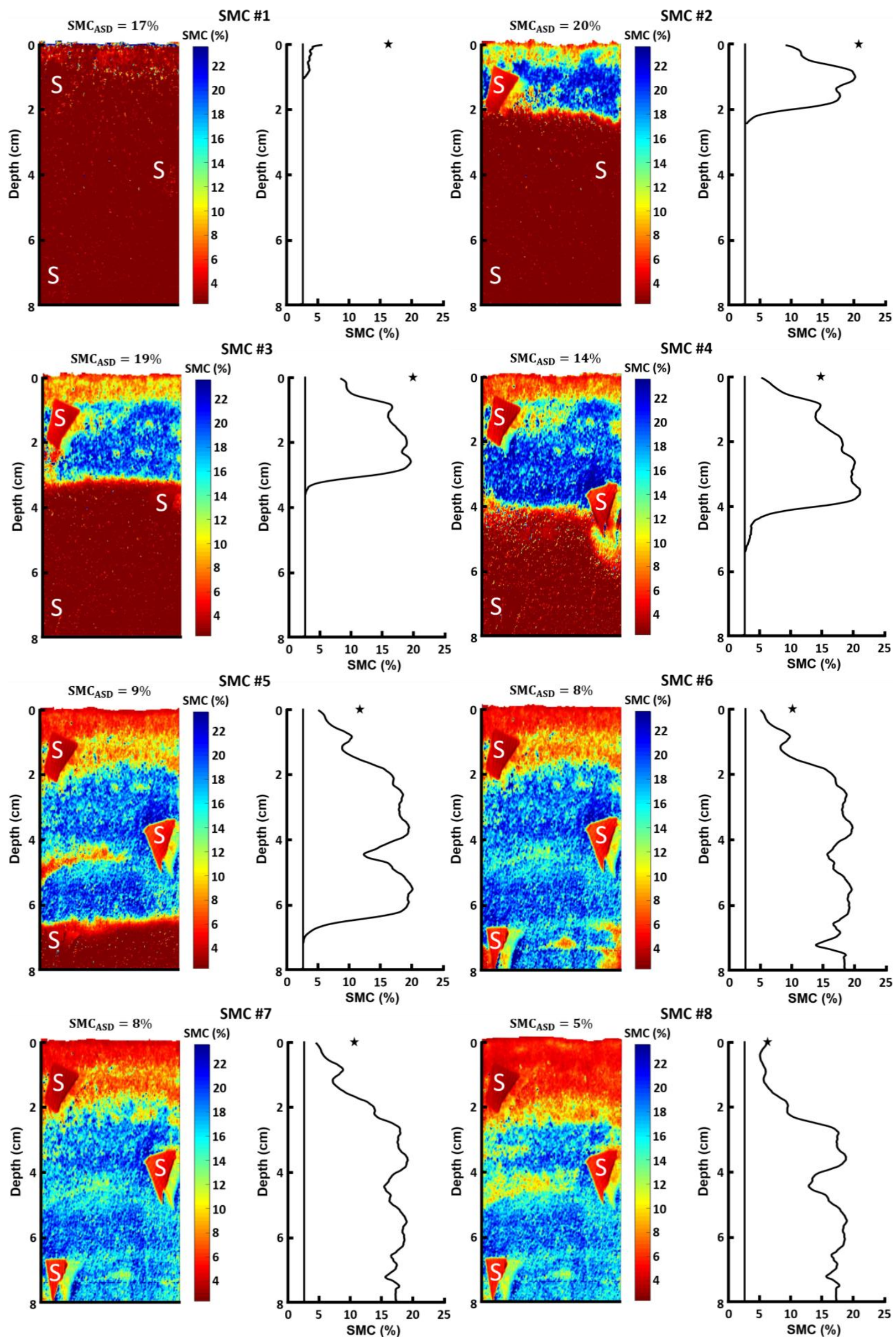

Fig. 12. SMC maps of the sand as a function of the amount of water poured and associated water content profiles. From top left to bottom right: moisture levels \#1 to \#8 (Table 2). $\mathrm{S}=$ piece of duct tape. The star points the SMC value measured at the top of the soil. 


\section{Discussion}

The water front takes longer to stabilize in the clay loam than in the sand, therefore the time elapsed between the addition of water on the soil and the radiance measurement is higher for the first soil $(\sim 50$ minutes max) than for the second one ( 15 minutes max) (Table 3). One reason is that water penetrates faster in the sand. This agrees with Darcy's law that describes the flow of a fluid through a porous medium. It stipulates that the hydraulic conductivity $K$ is much higher in coarse-grained soils (e.g., the sand) than in small-grained soils (e.g., the clay loam) due to the large intra-granular distance. Capillary forces are very low and the force of gravity prevails, so water tends to infiltrate without stagnating. Therefore, movement of water across the sand is much faster. On the contrary, in a clay loam soil, the capillary forces that are greater due to the short intra-granular distance counterbalance the gravitational forces applied on the water. In short, water naturally seeps into the sand and it penetrates into the clay only because of the increased pressure due to the addition of water to the water column. Another reason may be evaporation that dries the surface: the first stage occurs earlier for the sand than for the clay loam (e.g., Han and Zhou, 2013; Or et al., 2013; Song et al., 2014; Merz et al., 2014). However, only the capillary force explains the observations at a depth of $2 \mathrm{~cm}$ or below for the sand in such a short time.

The link between the hydraulic conductivity and the grain size may also explain the high standard deviation values in the sand (Fig. 8): for example, at moisture level \#5, one can see rapid variations in SMC at about $4.5 \mathrm{~cm}$ depth. This anomaly is certainly linked to a different particle size in this zone. Indeed, the larger the grains, the greater the percolation. Therefore, SMC is smaller in this area.

Another issue concerns the deep pixels where a non-zero SMC is predicted while water did not arrive at this depth yet (see SMC \#1 in Fig. 11). These pixels may correspond to pores in the dry soil, which create shadows that decrease the reflectance. Note that soil compaction is also likely to occur between two experiments, either because the aquarium is moved meanwhile, or because of the moistening itself. The model assimilates such low-reflectance pixels to a wet soil. 
For the sand, we also noticed that SMC determined with the ASD spectroradiometer did not exactly match SMC determined with the HySpex cameras at the top of the profile (Figs 11 and 12). This difference is due to the unevenness of surface moistening: the central part of the aquarium is wetter than 314 the edges, where water infiltration is monitored by cameras. In addition, SMC at the top of the soil is 315 difficult to determine accurately from the images.

316 Despite the issues mentioned, with regard to water content profiles, we recognize the three regimes 317 that have been identified by Al-Hamdan and Cruise (2010):

318 1) the soil has just been watered, it is wet on the surface but dry in depth (moisture levels \#1 to \#7 for the loam clay and moisture level \#1 for the sand);

2) water has entered into the soil, which is dry on the surface but wet in depth (moisture levels \#6 to \#8 for the sand);

Such a dynamic (or transitional) regime typically occurs several hours after a rain.

3) the soil is still dry in depth, but and has become dry again on surface after infiltration or evaporation (moisture levels \#2 to \# 4 for the sand).

Various techniques can be used in the laboratory to assess soil moisture profiles. Sadeghi et al. (2017) who reviewed the most common ones (X-ray micro-computed tomography, neutron radiography, and magnetic resonance imaging) explain that optical methods are easier, faster, and cheaper to implement. In particular, the spatial resolution is higher for equal soil volume. Moreover, our experiment enables to assess surface and in-depth SMC nearly simultaneously.

If the soil physical parameters are available, profile can also be computed thanks to theoretical hydrological models such as the HYDRUS computer software packages (Šimůnek et al., 2016). Although this approach is a powerful way to connect surface and subsurface SMC in a large number of cases, it is beyond the scope of this article. However, our experiment provide specialists with unique experimental data to run such models. 


\section{Conclusion}

We designed a new experiment to measure simultaneously soil surface reflectance and soil in-depth reflectance, and to study their evolution over space and time while pouring water onto a soil. We used the MARMITforSMC method to obtain high spatial resolution maps of SMC and the associated water profiles. We observed profiles commonly described in the literature, but with a spatial resolution rarely achieved.

As observed of Edwards et al. (2013) on sand, surface SMC is much lower than SMC at $3 \mathrm{~cm}$ depth about 15 to $20 \mathrm{~min}$ after a heavy rainfall $(20-30 \mathrm{~mm})$. For the clay loam, water penetrates uniformly into the soil. We also tried to compare the SMC profiles with measurements provided by TDR probes. While the agreement is good for the clay loam, there are discrepancies in the results for the sand. It would be interesting to perform complementary experiments with TDR arrays (Sheng et al., 2017) or to assess the shape of SMC profiles when evaporation occurs. Our experiment also indicates that, at least for some soils, it is necessary to improve the link between surface reflectance and SMC established using Petri dishes.

Studying other soils covering the texture triangle, like in Sadeghi et al. (2017), would be worthwhile, while keeping in mind that a large amount of matter $\left(\sim 350 \mathrm{~cm}^{3}\right)$ is needed to fill the aquarium. Several spaceborne hyperspectral sensors are under development (e.g., EnMap, HyspIRI, Shalom) or already operational (e.g., PRISMA) so that new remote sensing data will be soon available. The validation of semi-empirical relationships or radiative transfer models for SMC retrieval using these data is an important step before producing SMC maps routinely. In such a context, the comparison between surface SMC and in-depth SMC is a key point regarding the link between hyperspectral imagery and in situ measurements.

\section{Acknowledgements}

360 The PhD thesis of Aurélien Bablet was funded by ONERA and IPGP. This work was also supported by 
The authors would like to thank Philippe Déliot (ONERA) for his invaluable help during the

measurements with the HySpex cameras.

\section{References}

366

367

368

369

370

371

372

373

374

375

376

377

378

379

380

381

382

383

384

385

386

387

388

389

390

391

392

393

394

395

396

397

398

399

400

401

402

403

404

405

406

407

408

409

410

411

412

413

Al-Hamdan, O.Z., Cruise, J.F., 2010. Soil moisture profile development from surface observations by principle of maximum entropy. J. Hydrol. Eng. 15 (5), 327-337.

Bablet, A., Vu, P.V.H., Jacquemoud, S., Viallefont-Robinet, F., Fabre, S., Briottet, X., Sadeghi, M., Whiting, M.L., Baret, F., Tian, J., 2018. MARMIT: A multilayer radiative transfer model of soil reflectance to estimate surface soil moisture content in the solar domain (400-2500 nm). Remote Sens. Environ. 217, 1-17.

Bolten, J.D., Crow, W.T., Zhan, X., Jackson, T.J., Reynolds, C.A., 2010. Evaluating the utility of remotely sensed soil moisture retrievals for operational agricultural drought monitoring. IEEE J. Sel. Topics Appl. Earth Observ. Remote Sens. 3 (1), 57-66.

Brigot, G., Colin-Koeniguer, E., Plyer, A., Janez, F., 2016. Adaptation and evaluation of an optical flow method applied to coregistration of forest remote sensing images. IEEE J. Sel. Topics Appl. Earth Observ. Remote Sens. 9 (7), 2923-2939.

Ciani, A., Goss, K.U., Schwarzenbach, R.P., 2005. Light penetration in soil and particulate minerals. Eur. J. Soil Sci. 56 (5), 561-574.

de Wit, A.D., van Diepen, C.A., 2007. Crop model data assimilation with the Ensemble Kalman filter for improving regional crop yield forecasts. Agric. For. Meteorol. 146 (1-2), 38-56.

Edwards, B.L., Schmutz, P.P., Namikas, S.L., 2013. Comparison of surface moisture measurements with depthintegrated moisture measurements on a fine-grained beach. J. Coastal Res. 29 (6), 1284-1291.

Famiglietti, J.S., Rudnicki, J.W., Rodell, M., 1998. Variability in surface moisture content along a hillslope transect: Rattlesnake Hill, Texas. J. Hydrol. 210 (1-4), 259-281.

Folke, C., Carpenter, S., Walker, B., Scheffer, M., Elmqvist, T., Gunderson, L., Holling, C. S., 2014. Regime shifts, resilience, and biodiversity in ecosystem management Annu. Rev. Ecol. Evol. Syst. 35, 557-581.

Gaur, N., Mohanty, B.P., 2013. Evolution of physical controls for soil moisture in humid and subhumid watersheds. Water Resour. Res. 49 (3), 1244-1258.

Han, J., Zhou, Z., 2013. Dynamics of soil water evaporation during soil drying: Laboratory experiment and numerical analysis. Sci. World J. 2013, 240280.

Jana, R.B., Mohanty, B.P., 2012. A comparative study of multiple approaches to soil hydraulic parameter scaling applied at the hillslope scale. Water Resour. Res. 48 (2), W02520.

Joshi, C., Mohanty, B.P., 2010. Physical controls of near-surface soil moisture across varying spatial scales in an agricultural landscape during SMEX02. Water Resour. Res. 46 (12), W12503.

Kornelsen, K.C., Coulibaly, P., 2014. Root-zone soil moisture estimation using data-driven methods. Water Resour. Res. 50 (4), 2946-2962.

Koster, R.D., et al., 2004. Regions of strong coupling between soil moisture and precipitation. Science 305 (5687), 1138-1140.

Liang, J., Williams, D.R., Miller, D.T., 1997. Supernormal vision and high-resolution retinal imaging through adaptive optics. J. Opt. Soc. Am. A 14 (11), 2884-2892.

Merz, S., Pohlmeier, A., Vanderborght, J., van Dusschoten, D., Vereecken, H., 2014. Moisture profiles of the upper soil layer during evaporation monitored by NMR. Water resources research 50 (6), 5184-5195.

Montzka, C., Moradkhani, H., Weihermüller, L., Franssen, H.J.H., Canty, M., Vereecken, H., 2011. Hydraulic parameter estimation by remotely-sensed top soil moisture observations with the particle filter. J. Hydrol. 399 (3-4), 410-421.

Ochsner, T.E., Cosh, M.H., Cuenca, R.H., Dorigo, W.A., Draper, C.S., Hagimoto, Y., Kerr, Y.H., Njoku, E.G., Small, E.E., Zreda, M., Larson, K.M., 2013. State of the art in large-scale soil moisture monitoring. Soil Sci. Soc. Am. J. 77 (6), 1888-1919.

Okin, G., Painter, T., 2004. Effect of grain size on remotely sensed spectral reflectance of sandy desert surfaces. Remote Sens. Environ. 89 (3), 272-280.

Or, D., Lehmann, P., Shahraeeni, E., Shokri, N., 2013. Advances in soil evaporation physics-A review. Vadose Zone Journal 12 (4).

Perkins, E.J., 1963. Penetration of light into littoral soils. J. Ecol. 51 (3), 687-692. 
Rosenbaum, U., Bogena, H.R., Herbst, M., Huisman, J.A., Peterson, T.J., Weuthen, A., Western, A.W., Vereecken, H., 2012. Seasonal and event dynamics of spatial soil moisture patterns at the small catchment scale. Water Resour. Res. 48 (10), W10544.

Sadeghi, M., Sheng, W., Babaeian, E., Tuller, M., Jones S.B., 2017. High-resolution shortwave infrared imaging of water infiltration into dry soil, Vadose Zone J. 16 (13), doi:10.2136/vzj2017.09.0167.

Sadeghi, M., Babaeian, E., Tuller, M., Jones, S.B., 2018. Particle size effects on soil reflectance explained by an analytical radiative transfer model. Remote Sens. Environ. 210, 375-386.

Schreiner-McGraw, A.P., Vivoni, E.R., Mascaro, G., Franz, T.E., 2016. Closing the water balance with cosmicray soil moisture measurements and assessing their relation to evapotranspiration in two semiarid watersheds. Hydrol. Earth Syst. Sci. 20 (1), 329.

Schröter, I., Paasche, H., Dietrich, P., Wollschläger, U., 2015. Estimation of catchment-scale soil moisture patterns based on terrain data and sparse TDR measurements using a fuzzy c-means clustering approach. Vadose Zone J. 14 (11), doi:10.2136/vzj2015.01.0008.

Sheng, W., Zhou, R., Sadeghi, M., Babaeian, E., Robinson, D.A., Tuller, M., Jones, S.B., 2017. A TDR array probe for monitoring near-surface soil moisture distribution. Vadose Zone J. 16 (4), doi:10.2136/vzj2016.11.0112.

Šimůnek, J., van Genuchten, M.T., Šejna M., 2016, Recent developments and applications of the HYDRUS computer software packages, Vadose Zone J. 15 (7), doi:10.2136/vzj2016.04.0033.

Song, W., Cui, Y.J., Tang, A.M., Ding, W., Tran, T.D., 2013. Experimental study on water evaporation from sand using environmental chamber. Can. Geotech. J. 51 (2), 115-128.

Tester, M., Morris, C., 1987. The penetration of light through soil. Plant Cell Environ. 10 (4), 281-286.

Vereecken H., Huisman J.A., Bogena H., Vanderborght J., Vrugt J.A., Hopmans J.W., 2008. On the value of soil moisture measurements in vadose zone hydrology: A review. Water Resour. Res., 44 (4), W00D06.

Vereecken, H., Schnepf, A., Hopmans, J.W., Javaux, M., Or, D., Roose, T., Vanderborght, J., Young, M.H., Amelung, W., Aitkenhead, M., Allison, S.D., 2016. Modeling soil processes: Review, key challenges, and new perspectives. Vadose Zone J. 15 (5), doi:10.2136/vzj2015.09.0131.

Woolley, J.T., Stoller, E.W., 1978. Light penetration and light-induced seed germination in soil. Plant Physiol. 61 (4), 597-600. 